\title{
The Potential Mechanism of ZFX Involvement in Cell Growth
}

\author{
Mahboube Ganji-Arjenaki ${ }^{1}$, Modjtaba Emadi-Baygi ${ }^{1,2^{*}}$, Parvaneh Nikpour ${ }^{3,4,5}$ \\ ${ }^{1}$ Department of Genetics, Faculty of Basic Sciences,University of Shahrekord, Shahrekord, Iran. \\ ${ }^{2}$ Research Institute of Biotechnology, University of Shahrekord, Shahrekord, Iran. \\ ${ }^{3}$ Applied Physiology Research Center, Faculty of Medicine, Isfahan University of Medical Sciences, Isfahan, Iran. \\ ${ }^{4}$ Child Growth and Development Research Center, Research Institute for Primordial Prevention of Non-communicable Disease, Faculty of \\ Medicine, Isfahan University of Medical Sciences, Isfahan, Iran. \\ ${ }^{5}$ Department of Genetics and Molecular Biology, Faculty of Medicine, Isfahan University of Medical Sciences, Isfahan, Iran.
}

\section{Received: 17 Jan 2016}

Revised : 18 Feb 2016

Accepted: 10 Mar 2016

Corresponding Author: Modjtaba Emadi-Baygi,

Department of Genetics, Faculty of

Basic Sciences, Shahrekord University,

Shahrekord, Iran,

Phone: +983814424419

E-mail: emadi-m@ sci.sku.ac.ir

\begin{abstract}
Background: The zinc-finger X linked (ZFX) gene encodes a transcription factor that acts as a regulator of self-renewal of stem cells. Due to the role of ZFX in cell growth, understanding ZFX protein-protein interactions helps to clarify its proper biological functions in signaling pathways. The aim of this study is to define ZFX protein-protein interactions and the role of ZFX in cell growth.

Materials and Methods: The PIPs output includes three interacting proteins with ZFX: eukaryotic translation initiation factor 3 subunit I (EIF3I), eukaryotic translation initiation factor 3 subunit G (EIF3G) and protein nuclear pore and COPII coat complex component homolog isoform 3 (SEC13L1).

Results: As a cargo and transmembrane protein interacting with Sec13, eIF3I and eIF3G, ZFX mediates cargo sorting in COPII vesicles at ER exit sites. While traveling to cis-Golgi, eIF3I is phosphorylated by the mechanistic target of rapamycin (mTOR). Proteins transport by COPI vesicles to the nucleusouter site layer containing SEC13 via the contribution of microtubules. EIF3G and eIF3I interact with coatomer protein complex subunit beta 2 (COPB2) that helps to enclose ZFX in COPI vesicle. ZFX and eIF3G enter nucleolus where activation of transcription from pre rDNA genes occurs.
\end{abstract}

Conclusion: We proposed a model in which ZFX is involved in cell growth by promoting the transcription of rDNA genes.

Keywords: ZFX; Cell growth; Cancer stem cells; rDNA genes;Protein-protein interactions

\section{Introduction}

Located in Xp21.3-Xp22. 1 and identified as a result of its strong homology to ZFY, the ZFX gene may function in sex determination and escapes $X$ inactivation $(1,2)$. Differential splicing of ZFX transcript results in five variants. Variants 1,2 and 3 encode for protein isoform I, variant 4 encodes for isoform II and variant 5 encodes for isoform III. All isoforms encode proteins composed of a highly acidic amino-terminal domain, a basic putative nuclearlocalization signal and only isoforms I and II contain carboxy - terminal zinc - finger domain(3). Due to the presence of an acidic domain in ZFX protein, similar to the activation domain of transcription factors, and a potential nucleic acid-binding domain of 13 "zinc ringers", Palmer et al suggested that ZFX may be a plausible transcription facto (4). L'Haridon et al. provided the first demonstration that the ZFX gene encodes a bona fide transcription factor (5). Zinn et al mapped one or more Turner syndrome traits, including short stature, ovarian failure, high-arched palate, and autoimmune thyroid disease in a critical region in Xp11.2-p22.1 (6), implicating the importance of ZFX during game to genes is development and in efficient gametogenesis during 
adulthood (7). Of note, Galan-Caridad et al. recently showed that $\mathrm{Zfx}$ is a shared transcriptional regulator of embryonic (ESCs) and hematopoietic stem cells (HSCs) (8). Furthermore, Harel et al. reported that ZFX-overexpressing human ESCs produce more colonies with larger size compared to controls (9). Recently, Huang et al. showed that ZFX is upregulated in cancer stem-like cells in esophageal carcinoma cell lines (10). Furthermore, ZFX is overexpressed in several types of malignancies including diffuse large B-cell and follicular lymphoma (11) and prostate cancer (12). Moreover, it is overexpressed in gastric cancer and our recent work showed a positive correlation between ZFX isoform $3 /$ variant 5 transcript and gastric tumor size. $(13,14)$ and gliomas. We also found thatZFX gene expression was significantly correlated with central features of the neoplastic phenotype $(15,16)$.Knocking-down of ZFX in Hep-2, U251 and PC-3 human cancerous cell lines showed that this gene is important in the proliferation and apoptosis of the cells (15). On the other hand, previous studies on ZFX gene has also focused on exploring ZFX target genes and did not analyze its protein-protein interactions. Proteinprotein interactions inter-link a huge network of genes and involve in almost every biological process under physiological conditions (17). Due to the role (s) of ZFX in various biological processes such as cell growth, survival, differentiation, cell cycle and apoptosis, understanding ZFX protein-protein interactions helps to clarify its proper biological functions that in turn leads to find its involvement in disease-associated signaling pathways. To this end, the aim of the current study is to define ZFX proteinprotein interactions and the role of $\mathrm{ZFX}$ in cell growth. We searched PIPs (human protein-protein interaction prediction database) to find ZFX interacting proteins (18).

\section{Materials and Methods}

We performed literature mining using various keywords, including "ZFX", "cancer", "stem cell", "transcription factor". To explore the possible ZFX protein-protein interactions, we referred to several databases including human protein-protein interaction prediction (PIPs) (18), the human protein interaction (HPID) (19), the database of interacting proteins (DIP) (20), and the molecular interaction (MINT) (21). Furthermore, we deduced the functional importance of the predicted ZFX protein-protein interactions using several servers and tools including prediction of cellular role, enzyme class and gene ontology category (ProtFun) (22), PredictProtein (23) ProtParam (24).

\section{Results \\ Predicted protein-protein interactions}

Our data mining in relevant databases to find the ZFX protein-protein interactions did not retrieve any relevant result except for PIPs. As is evident in table 1, the PIPs output includes three proteins: EIF3I (eIF3S2), EIF3G (eIF3S4) and SEC13L1.

Table 1. ZFX interacting proteins as predicted by PIPs. The intensity of the color corresponds to the likelihood of the interaction. The Score column is the predicted score of interaction between the two proteins.

\begin{tabular}{llll}
\hline Protein1 & Protein2 & Name of Protein 2 & Module Scores \\
\hline \multirow{2}{*}{ ZFX } & EIF3S2 & $\begin{array}{l}\text { TRIP1: Eukaryotic translation initiation } \\
\text { factor 3 subunit 2 }\end{array}$ & \\
\cline { 2 - 5 } & EIF3S4 & $\begin{array}{l}\text { Eukaryotic translation initiation factor 3 } \\
\text { subunit 4 }\end{array}$ & \\
\cline { 2 - 4 } & SEC13L1 & N/A & \\
\hline
\end{tabular}

\section{Discussion}

EIF3I and EIF3G are two subunits of eIF3 that binds to the $40 \mathrm{~S}$ ribosome in an early step of translation initiation and promotes the binding of methionyltRNAi and mRNA (25). SEC13 is a Trp - Asp (WD) repeat protein, localized to the endoplasmic reticulum (ER) exit sites and required for COPII vesicle biogenesis and a shuttle protein between the nucleus and the cytoplasm (26).
Plausible consequences of the protein-protein interactions on post-translational modification (PTM) of ZFX

ZFX, EIF3I and EIF3G genes are transcribed by Ying Yang 1 (YY1) transcription factor (27) and then are translocated to the cytoplasm for translation. The ZFX mRNA may be translated by ribosomes bound to the rough endoplasmic reticulum (RER) since it has an ASN (Asparagine) glycosylation site (28). The 
nascent ZFX protein then may enter the lumen of RER by a doughnut shaped poreconsisting of Sec61 protein translocator (29). We postulated that ZFX is then transported to the Golgi apparatus by COPII vesicles enclosed by SEC13-SEC31 heterotetramer for post-translational modification (PTM) such as phosphorylation, the addition of $\mathrm{ZN}$ ion and acetylation $(28,30)$. All of the proteins that need to leave the ER, do not contain a signal for direct binding to Sec24.
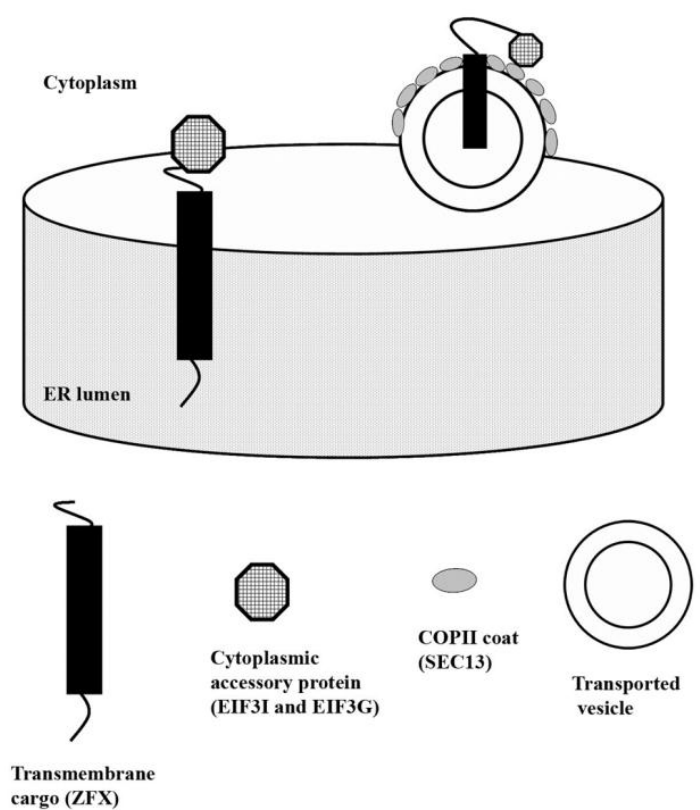

Figure 1. Cargo (ZFX) sorting mediating by the adaptor protein (SEC13) in COPII vesicles at ER exit sites (modified from Zanetti et al. 2011). The ZFX mRNA may be translated by ribosomes bound to the rough endoplasmic reticulum (RER), the nascent ZFX protein then may enter the lumen.

Some of these proteins might interact with a transport adaptor like SEC13 (containing a WD repeat region) (22), and thus be included in the COPII vesicle through an indirect interaction (31). Due to the presence of an NLS (nuclear localization signal) domain in ZFX protein (32), it can be regarded as a cargo. This cargo may interact with SEC13 (33) as predicated by PIPs (Table 1). Furthermore, the presence of an $\mathrm{N}$-myristoylation site and a beta barrel structure in ZFX protein implicates that it is a transmembrane protein (TMP) (22). Being as a cargo and transmembrane protein interacting with Sec13, ZFX might interact with eIF3I and eIF3G (as cytoplasmic accessory proteins which are adaptor proteins involving in signal transduction) to mediate cargo sorting in COPII vesicles at ER exit sites. As the size and function of a COPII vesicle coat are regulated by ubiquitin (34), and ZFX, eIF3I, eIF3G and SEC13 proteins interact with ubiquitin $\mathrm{C}$ (UBC)
(35), we postulated that the above-mentioned process of formation of ZFX-containing COPII vesicles may be plausible (Figure 1).

After disjoining of the ER exit site to Golgi network, the COPII coat is disassembled by GTP hydrolysis and Sec13-Sec31 cage is depolymerized while SEC23-24 complex is retained (30). The remaining vesicle travels to cis-Golgi for other modifications such as: addition of $\mathrm{Zn++}$, acetylation and amidation (28). While traveling to cis-Golgi, eIF3I is phosphorylated by mammalian target of rapamycin (mTOR) (36) localized to the endoplasmic reticulum and Golgi (35). Transported proteins from Golgi to the nucleus are carried by COPI vesicles to nuclear pore complex containing SEC13 in outer site layer (37) via the contribution of microtubules (38). The coat structure of COPI vesicles consists of the heptameric coatomer protein complex that COPB2 (beta'-COP) (39) protein is a part of this complex (40). As predicted by PIPs, eIF3G and eIF3I interact with COPB2 (Figure 2)

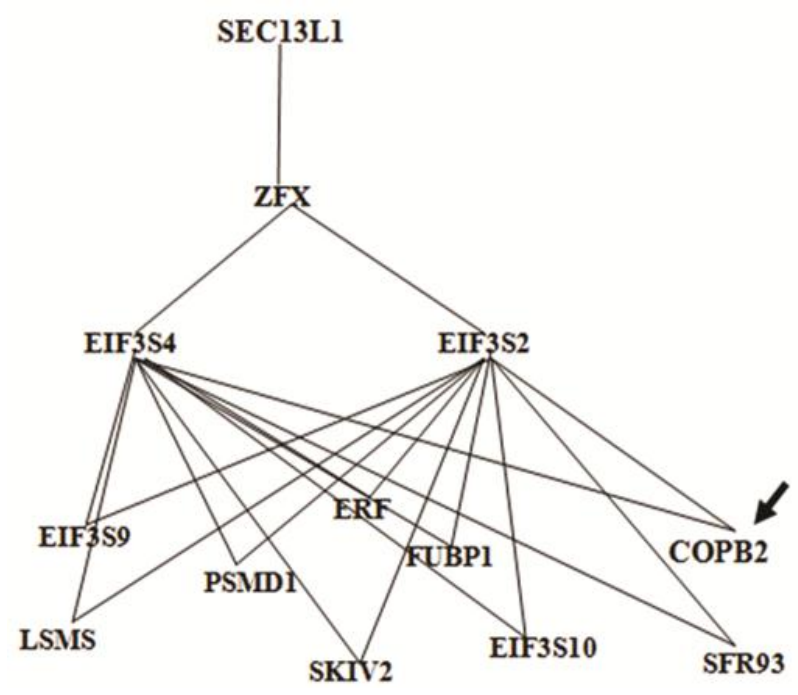

Figure 2. eIF3I and eIF3G interacting proteins as predicted by PIPs. The arrow shows COPB2 protein.

Therefore, we postulated that this interaction may help to enclose ZFX in COPI vesicles (41) (Figure 3). As eIF3I contains the WD-40 domain, it is plausible that it functions as an adaptor protein (42).

COPI vesicle coat proteins are disassembled by hydrolysis of GTP (38) and lyase enzymatic property of eIF3I (22) may result in the breakage of (N-C) link that binds myristic acid in the vesicle membrane to a nitrogen of an amino acid in eIF3I protein, therefore eIF3I protein disassociates from eIF3G and ZFX proteins. eIF3I is a scaffold protein for assembly of eIF3 factor subunits (42) in which bound eIF3 
inhabits binding of $60 \mathrm{~S}$ subunit to $40 \mathrm{~S}$ subunit and promotes the recruitment of the $40 \mathrm{~S}$ ribosomal subunit to the mRNAs (25) and therefore remaining of the eIF3I near NPC is rational. However, eIF3G possesses two RNA binding domains (RBS) (43); therefore, it may function in transcription regulation as predicted by ProtFun 2.2 server (22). Moreover, it can bind to $18 \mathrm{~S}$ rRNA (44). Taken together, it is possible that ZFX and eIF3G enter the nucleolus where they activate transcription from pre rDNA genes. The involvement of a zinc finger protein in rRNA gene transcription has been reported for Basonuclin, a zinc finger protein of keratinocytes (45). Furthermore, there are multiple zinc finger recognition sites in the promoter of rDNA genes as predictedby zinc finger tools (46). Besides, due to the possible dual role of eIF3G in transcription regulation and binding to the transcript of rDNA genes to prevent them from the assembly of ribosome; we proposed a model in which ZFX and its interacting proteins includingeIF3G contribute to cell growth by promoting the transcription of rDNA genes in the nucleolus.

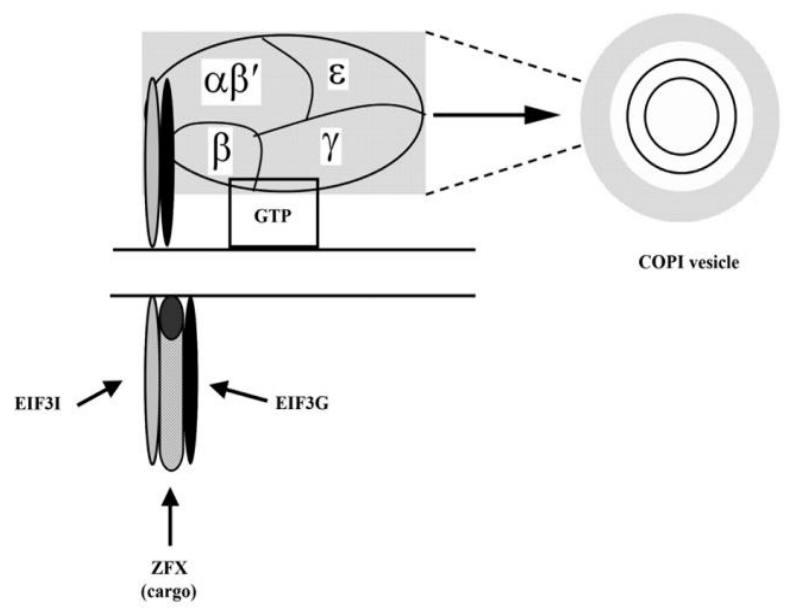

Figure 3. Schematic representation of the assembly of COPI vesicle containing ZFX (modified from Bethune et al. 2006).

\section{Conclusion}

In our model, we proposed that ZFX may interact with EIF3I, EIF3G and SEC13L1. After transcription, the ZFX mRNA may enter the lumen of the rough endoplasmic reticulumby sec61. Being as a cargo and transmembrane protein interacting with Sec13, ZFX might interact with eIF3I and eIF3G to mediate cargo sorting in COPII vesicles totransfer to the Golgi apparatus for PTM. Interaction between eIF3G, eIF3I and COPB2 may help to enclose ZFX in the COPI vesicles in the Golgi apparatus. Once COPI vesiclesdisassemble, the eIF3I may remainnear the NPC, while ZFX and eIF3G may enter the nucleolus where they activate transcription from pre rDNA genes.

\section{Acknowledgements}

We thank the staff at Department of Genetics in Faculty of Basic Sciences for their assistance.

\section{Author Contributions}

All authors made substantial contributions to conception and design, acquisition of data, analysis and interpretation of data; all authors participated in drafting the article or revising it critically for important intellectual content. All authors gave final approval of the version to be submitted in any revised version.

\section{Conflict of Interest}

Authors declare no conflict of interest.

\section{Support/Funding}

This research was partially funded by the University of Shahrekord.

\section{References}

1. Vakili Azghandi M, Nasiri M, Shamsa A, Jalali M, Shariati MM. Comparative In silico Study of Sex-Determining Region Y (SRY) Protein Sequences Involved in Sex-Determining. Rep Biochem Mol Biol. 2016; 4(2):76-81. PMID: 27536700

2. Li C, Li H, Zhang T, Li J, Ma F, Li M, et al. ZFX is a Strong Predictor of Poor Prognosis in Renal Cell Carcinoma. Med Sci Monit. 2015; 21:3380-5. PMID: 26540164

3. Huret J-L, Senon S. Atlas of genetics and cytogenetics in oncology and haematology. 2006.

4. Decarpentrie F, Vernet N, Mahadevaiah SK, Longepied G, Streichemberger E, Aknin-Seifer I, et al. Human and mouse ZFY genes produce a conserved testis-specific transcript encoding a zinc finger protein with a short acidic domain and modified transactivation potential. Hum Mol Genet. 2012; 21(12):2631-45. PMID: 22407129

5. Murray JS, Murray EH. TE-domestication and horizontal transfer in a putative Nef-AP1mu mimic of HLA-A cytoplasmic domain re-trafficking. Mob Gent Elements. 2016; 6(3):e1176634. PMID: 27511291

6. Viuff MH, Trolle C, Wen J, Jensen JM, Norgaard BL, Gutmark EJ, et al. Coronary artery anomalies in Turner Syndrome. J Cardiovasc Comput Tomogr. 2016. PMID: 27522573

7. Blanes MS, Tsoi SC, Dyck MK. Accurate and Phenol Free DNA Sexing of Day 30 Porcine Embryos by PCR. J Vis Exp. 2016; 14(108):53301. PMID: 26966900.

8. Galan-Caridad JM, Harel S, Arenzana TL, Hou ZE, Doetsch FK, Mirny LA, et al. Zfx controls the self-renewal of embryonic and hematopoietic stem cells. Cell. 2007 20; 129(2):345-57. PMID: 17448993.

9. Harel S, Tu EY, Weisberg S, Esquilin M, Chambers SM, Liu B, et al. ZFX controls the self-renewal of human embryonic stem cells. PloS one. 2012; 7(8):e42302. PMID: 22879936 
10. Huang D, Gao Q, Guo L, Zhang C, Jiang W, Li H, et al. Isolation and identification of cancer stem-like cells in esophageal carcinoma cell lines. Stem Cells Dev. 2009; 18(3):465-73. PMID: 18680391 .

11. Sakhinia E, Glennie C, Hoyland JA, Menasce LP, Brady G, Miller $\mathrm{C}$, et al. Clinical quantitation of diagnostic and predictive gene expression levels in follicular and diffuse large B-cell lymphoma by RT-PCR gene expression profiling. Blood. 2007; 109(9):3922-8. PMID: 17255358.

12. Dasari VK, Goharderakhshan RZ, Perinchery G, Li LC, Tanaka Y, Alonzo J, et al. Expression analysis of Y chromosome genes in human prostate cancer. J Urol. 2001; 165(4):1335-41. PMID: 11257712 .

13. Nikpour P, Emadi-Baygi M, Mohammad-Hashem F, Maracy MR, Haghjooy-Javanmard S. Differential expression of ZFX gene in gastric cancer. J Biosci. 2012; 37(1):85-90. PMID: 22357206.

14. Rahmati S, Emadi-Baygi M, Nikpour P, Emadi-Andani E. Expression profile of ZFX isoform3/variant 5 in gastric cancer tissues and its association with tumor size. Iran J Basic Med Sci. 2014; 17(10):767-71. PMID: 25729545

15. Zhou Y, Su Z, Huang Y, Sun T, Chen S, Wu T, et al. The Zfx gene is expressed in human gliomas and is important in the proliferation and apoptosis of the human malignant glioma cell line U251. J Exp Clin Cancer Res. 2011; 30:114. PMID: 22185393

16. Afzali A, Emadi-Baygi M, Nikpour P, Nazemroaya F, Kheirollahi M. Expression of ZFX gene correlated with the central features of the neoplastic phenotype in human brain tumors with distinct phenotypes. Adv Biomed Res. 2015; 4:179. PMID: 26605218

17. Khan SH, Ahmad F, Ahmad N, Flynn DC, Kumar R. Proteinprotein interactions: principles, techniques, and their potential role in new drug development. J Biomol Struct Dyn. 2011; 28(6):92938. PMID: 21469753

18. McDowall MD, Scott MS, Barton GJ. PIPs: human proteinprotein interaction prediction database. Nucleic Acids Res. 2009; 37(Database issue):D651-6. PMID: 18988626.

19. Han K, Park B, Kim H, Hong J, Park J. HPID: the Human Protein Interaction Database. Bioinformatics. 2004; 20(15):246670. PMID: 15117749 .

20. Xenarios I, Salwinski L, Duan XJ, Higney P, Kim SM, Eisenberg D. DIP, the Database of Interacting Proteins: a research tool for studying cellular networks of protein interactions. Nucleic Acids Res. 2002; 30(1):303-5. PMID: 11752321.

21. Chatr-aryamontri A, Ceol A, Palazzi LM, Nardelli G, Schneider MV, Castagnoli L, et al. MINT: the Molecular INTeraction database. Nucleic Acids Res. 2007; 35(Database issue):D572-4. PMID: 17135203.

22. Jensen LJ, Gupta R, Staerfeldt H-H, Brunak S. Prediction of human protein function according to Gene Ontology categories. Bioinformatics. 2003; 19(5):635-42. PMID: 12651722

23. Rost B, Yachdav G, Liu J. The PredictProtein server. Nucleic Acids Res. 2004; 32(Web Server issue):W321-6. PMID: 15215403.

24. Sathyan N, Philip R, Chaithanya E, Anil Kumar P. Identification and molecular characterization of molluskin, a
histone-H2A-derived antimicrobial peptide from molluscs. ISRN Mol Biol. 2012; 2012:219656. PMID: 27335663

25. Masutani $\mathrm{M}$, Sonenberg $\mathrm{N}$, Yokoyama S, Imataka $\mathrm{H}$. Reconstitution reveals the functional core of mammalian eIF3. EMBO J. 2007; 26(14):3373-83. PMID: 17581632.

26. Tang BL, Zhang T, Low DY, Wong ET, Horstmann H, Hong W. Mammalian homologues of yeast sec31p. An ubiquitously expressed form is localized to endoplasmic reticulum (ER) exit sites and is essential for ER-Golgi transport. J Biol Chem. 2000; 275(18):13597-604. PMID: 10788476

27. Trabucco SE, Gerstein RM, Zhang H. YY1 Regulates the Germinal Center Reaction by Inhibiting Apoptosis. J Immunol. 2016; 197(5):1699-707. PMID: 27448584.

28. Rost B, Yachdav G, Liu J. The PredictProtein server. Nucleic Acids Res. 2004; 32(suppl 2):W321-6.

29. Li H, Zheng H, Li L, Shen X, Zang W, Sun Y. The Effects of Matrix Metalloproteinase-9 on Dairy Goat Mastitis and Cell Survival of Goat Mammary Epithelial Cells. PloS one. 2016; 11(8):e0160989. PMID: 27518717.

30. Jensen D, Schekman R. COPII-mediated vesicle formation at a glance. J Cell Sci. 2011; 124(Pt 1):1-4. PMID: 21172817

31. Baines AC, Zhang B. Receptor-mediated protein transport in the early secretory pathway. Trends Biochem Sci. 2007; 32(8):3818. PMID: 17618120

32. Ma $\mathrm{H}$, Yang $\mathrm{F}$, Lian $\mathrm{M}$, Wang $\mathrm{R}$, Wang $\mathrm{H}$, Feng $\mathrm{L}$, et al Dysregulation of zinc finger protein, X-linked (ZFX) impairs cell proliferation and induces apoptosis in human oral squamous cell carcinorma. Tumour Biol. 2015; 36(8):6103-12. PMID: 25916205.

33. Copic A, Latham CF, Horlbeck MA, D'Arcangelo JG, Miller EA. ER cargo properties specify a requirement for COPII coat rigidity mediated by Sec13p. Science. 2012; 335(6074):1359-62. PMID: 22300850.

34. Jin L, Pahuja KB, Wickliffe KE, Gorur A, Baumgartel C, Schekman R, et al. Ubiquitin-dependent regulation of COPII coat size and function. Nature. 2012; 482(7386):495-500. PMID: 22358839

35. Liu X, Zheng XF. Endoplasmic reticulum and Golgi localization sequences for mammalian target of rapamycin. Mol Biol Cell. 2007; 18(3):1073-82. PMID: 17215520

36. Harris TE, Chi A, Shabanowitz J, Hunt DF, Rhoads RE, Lawrence JC, Jr. mTOR-dependent stimulation of the association of eIF4G and eIF3 by insulin. EMBO J. 2006; 25(8):1659-68. PMID: 16541103

37. Enninga J, Levay A, Fontoura BM. Sec13 shuttles between the nucleus and the cytoplasm and stably interacts with Nup96 at the nuclear pore complex. Mol Cell Biol. 2003; 23(20):7271-84. PMID: 14517296

38. Nickel W, Brugger B, Wieland FT. Vesicular transport: the core machinery of COPI recruitment and budding. J Cell Sci. 2002; 115(Pt 16):3235-40. PMID: 12140255

39. Khvorova A, Reynolds A, Leake D, Marshall W, Read S, Scaringe S. siRNA targeting coatomer protein complex, subunit beta 2 (COPB2). Google Patents; 2009. 
40. Bethune J, Wieland F, Moelleken J. COPI-mediated transport. J Membr Biol. 2006; 211(2):65-79. PMID: 17041781.

41. Munro S. Organelle identity and the organization of membrane traffic. Nat Cell Biol. 2004; 6(6):469-72. PMID: 15170453.

42. Ahlemann M, Zeidler R, Lang S, Mack B, Munz M, Gires O. Carcinoma-associated eIF3i overexpression facilitates mTORdependent growth transformation. Mol Carcinog. 2006; 45(12):957-67. PMID: 16929481

43. Conrad AH, Zhang Y, Tasheva ES, Conrad GW. Proteomic analysis of potential keratan sulfate, chondroitin sulfate A, and hyaluronic acid molecular interactions. Invest Ophthalmol Vis Sci 2010; 51(9):4500-15. PMID: 20375348
44. Cuchalová L, Kouba T, Herrmannová A, Dányi I, Chiu W-l, Valášek L. The RNA recognition motif of eukaryotic translation initiation factor $3 \mathrm{~g}$ (eIF3g) is required for resumption of scanning of posttermination ribosomes for reinitiation on GCN4 and together with eIF3i stimulates linear scanning. Mol Cell Biol. 2010; 30(19):4671-86.

45. Prenzler F, Fragasso A, Schmitt A, Munz B. Functional analysis of ZFP36 proteins in keratinocytes. Eur J Cell Biol. 2016; 95(8):277-84. PMID: 27182009.

46. Marchisio MA, Stelling J. Computational design tools for synthetic biology. Curr Opin Biotechnol. 2009; 20(4):479-85. PMID: 19758796 